\title{
Suomen ja viron johdostyyppien suhteista
}

\author{
HANNU REMES \\ Itä-Suomen yliopisto
}

Tiivistelmä. Sekä suomen että viron tavallisimmat sananmuodostuskeinot ovat yhdistäminen ja johtaminen. Johto-oppi on alue, johon kielenopetus ei ole kovinkaan paljon kiinnittänyt lähisukukielen sanaston omaksumisessa huomiota. Kuitenkin suomalaisia ja virolaisia helpottaa toistensa kielten opiskelussa monien yhteisten johdostyyppien esiintyminen, mutta toisaalta ongelmia saattavat aiheuttaa äidinkielelle vieraat tyypit. Aina eivät sitä paitsi johtosuhteet eikä tuttujenkaan johdinten käyttö ole kielten kesken samanlaisia.

Artikkelissa tarkastellaan suomen ja viron kirjakielten johdostyyppien suhteita. Naapurikielten opiskelussa on nomini- ja verbijohdosten osalta otettava huomioon useita seikkoja. Silloinkin kun kielissä esiintyy samalla johtimella muodostettavia sanoja, eivät johdosten merkitykset ole läheskään aina samanlaiset. Yhteisen johtimen käytössä saattaa myös olla sanaluokkakohtaisia eroja, ja johtimen käytön laajuus vaihtelee kielittäin.

Toisinaan kielet eroavat toisistaan siten, että samantyyppisten johdosten kantasanat kuuluvat eri sanaluokkiin. On myös mahdollista, että yhteisten johdostyyppien semanttisissa piirteissä on selkeitä kielikohtaisia eroja. Esimerkiksi virossa ei esiinny kuratiivisia ja kaptatiivisia verbejä, vaikka sellaisia suomessa muodostavilla johtimilla onkin kielessä vastineet.

Suomen ja viron johtosuhteita kirjavoittaa niin ikään se, että toisessa kielessä voi esiintyä yhteisen johdostyypin jakautumista useammaksi tyypiksi tai eri tyyppien yhdistymistä. On myös 
tavallista, että johdostyyppi puuttuu täysin toisesta kielestä. Joskus puuttuminen on synkronista, ja vanhasta johdostyypistä kertoo vielä taivutustyyppi. Suomen ja viron morfologisten järjestelmien vertailu osoittaa, että kielten välillä on erilaisuutta suhteellisesti enemmän johto-opissa kuin taivutuksessa ja nominien johtamisessa enemmän kuin verbiderivaatiossa.

Avainsanat: kontrastiivinen tutkimus; derivaatio; johdostyypit; johtimet; suomi; viro

\section{Johdanto}

Johto-oppi on alue, johon kielenopetus ei vieraan kielen sanaston omaksumisessa kohdista yleensä kovinkaan paljon huomiota, vaikka sen säännönmukaisuuksiin perehtyminen voisi helpottaa oppimista ja esimerkiksi auttaa opiskelijaa tuottamaan produktiiveilla johtimilla hänen leksikostaan vielä puuttuvia sanoja (ks. esim. Simon 2007: 295, 300). Lähisukuiset suomi ja viro ovat tunnetusti kieliä, joiden sananmuodostuksessa juuri johtaminen on yhdistämisen ohella keskeisellä sijalla, ja kielet hyödyntävät moninaisesti tätä mahdollisuutta.

Ison suomen kieliopin (ISK 2004: 180) mukaan kirjakielessämme on kaikkiaan toistasataa johdinta. Eesti keele grammatika I:ssä (EKG I) puolestaan esitellään noin yhdeksänkymmenen viron johtimen käyttöä. Luvut ovat kuitenkin tulkinnanvaraisia muun muassa siksi, ettei aina ole itsestään selvää, onko kyse yhden johtimen varianteista vai eri johtimista. Käytetäänkö suomessa esimerkiksi saman johdinmorfeemin allomorfeja vai itsenäisiä johtimia $m A$ - (ajatel/ma, muistel/ma, viljel/mä) ja (e) $\operatorname{lm} A$-nominijohdoksissa (must/elma, une/lma) tai $i$ - (kuokk/i/a, nuij/i/a, poik/i/a) ja Oi-verbijohdoksissa (harav/oi/da, vispil/öi/dä, vasik/oi/da, vrt. kantas. mon. vispilö/i/tä, vasiko/i/ta; huom. lapioidatyyppiset $o$-/ö-vartaloiseen kantasanaan perustuvat tapaukset; Hakulinen 1979: 282-284, vrt. Vesikansa 1977: 101, 110)? Vastaavasti viron kielen johtoseikkoja tarkastellessa voi pohtia, kuuluvatko samaan joh-

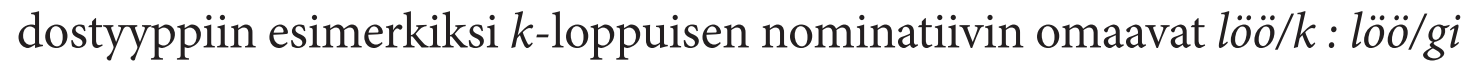


'lyönti', lennu/k : lennu/ki 'lentokone' ja käi/k: käi/gu 'käynti', rünna/k: rünna/ku 'hyökkäys; rynnäkkö, kuten yleensä esitetään (esim. EKG I: 519-520; Kasik 1996: 98-99; vrt. sm. levi/kki, lenno/kki ja era/kko, rynnä/kkö). Ja ovatko sekä s : sa -adjektiivit (ilu/s : ilu/sa 'kaunis', kuulu/s : kuul/sa 'kuuluisa') että las : la -adjektiivit (suu/las : suu/la, õgi/las : ógi/la 'ahne') samassa johdostyypissä (EKG I: 593; Kasik 1996: 150), vai olisiko aihetta katsoa ne eri tyypeiksi (vrt. sm. kuulu/isa : kuulu/isa/n, suu/las : suu/laa/n)? Viron johdosten van/us 'ikä' ja vana/dus 'vanhuus' yhteydessä on syytä kysyä, muodostetaanko saman johtimen varianteilla erimerkityksisiä sanoja, niin kuin esimerkiksi Eesti keele grammatika (EKG I: 490; ks. Hakulinen 1979: 144-145) katsoo, vai olisiko synkroniselta kannalta puhuttava kahdesta eri johtimesta. Kontrastiivisesta näkökulmasta voivat esimerkkeinä mainittujen johdinainesten suhteet tietysti hahmottua erilaisiksi kuin vain yhden kielen piirissä pysyttäessä.

Suomen ja viron johdostyyppejä vertailtaessa voi helposti havaita, että kielissä on koko joukko yhteisiä piirteitä, mutta lähisukuisuudesta huolimatta myös merkittäviä eroja. Tuttujen johdinten lisäksi on runsaasti kielikohtaisia johtimia, jotka puuttuvat toisesta kielestä (ainakin kirjakielestä), ja yhteistenkin johdinten produktiivius sekä johtosuhteet saattavat olla erilaisia ja johtaa toisinaan petollisten ystävien aiheuttamiin ongelmiin, kuten esimerkiksi tapauksessa sm. hallitus $(<$ hallita $)$ ja vir. hallitus ('home' < hallitada < hall 'harmaa'). Tarkastelen seuraavassa muutamia keskeisiä seikkoja, jotka on syytä ottaa naapurikielten opiskelussa nomini- ja verbijohdosten osalta huomioon.

\section{Kielissä yhteinen johdostyyppi}

Yksinkertaisin tilanne vallitsee silloin, kun suomessa ja virossa on yhteinen johdostyyppi. Tällöin johdoksia muodostetaan etymologisesti toisiaan vastaavilla johtimilla, joiden asussa voi tietysti olla kielihistoriallisen kehityksen aiheuttamia äänne-eroja, esimerkiksi sm. $-j A$ ja vir. -ja (myyjä, ostaja mü̈̈ja, ostja), sm. -minen ja vir. -mine (tuleminen, laulaminen tulemine, laulmine) sekä sm. - tA- ja vir. -t(a)-, -da- (päästää, 
parantaa päästa, parandada). Johdokset saattavat poiketa toisistaan semanttisesti ainakin jossain määrin, kuten osoittavat muun muassa samantyyppiset adjektiivit sm. tukeva ja vir. tugev : tugeva 'voimakas, vahva'. Johdinten produktiiviussuhteissa voi esiintyä kielten välillä suuriakin eroja. Esimerkiksi ryhmää mutta osin myös paikkaa ilmaisevalla suomen tavallisella (i)stO-johdostyypillä (laivasto, koivisto) on virossa äänteellisenä vastineena vähäkäyttöinen (i)stu-tyyppi, johon kuuluvat sanat ovat enimmäkseen oppitekoisia erikoisalojen termejä (teatmestu 'kirjaston tietokanta', ajastu 'aika, ajanjakso, (aika)kausi', järvistu maant. 'toisiinsa liittyvien järvien alue'). Joukossa on myös muutamia suomesta lainattuja johdoksia, kuten kinnistu 'kiinteistö' ja nimistu 'nimistö, nimiluettelo'. Tavallista on, että (i)stO-johdoksiamme vastaavat virossa semanttisesti stik-johdostyyppiin kuuluvat substantiivit (esim. sm. laivasto, sanasto, aakkosto, vuoristo vir. laevastik, sõnastik, tähestik, mäestik; Remes 2006: 236).

Kielten yhteisten johdostyyppien käytössä tavataan toisinaan sanaluokkakohtaisia eroja. Suomessa voivat esimerkiksi nimiin perustuvat lAinen-johdokset, kuten ruotsalainen, tallinnalainen, balttilainen, luterilainen, olla sekä substantiiveja että adjektiiveja, mutta virossa vastaavat lane-johdokset rootslane, tallinlane, baltlane ja luterlane ovat aina vain henkilöä tarkoittavia substantiiveja; adjektiivista käyttöä ( ${ }^{*}$ rootslane auto) niillä ei ole.

Vielä suurempi ero tulee vastaan suomen llinen-johdosten yhteydessä. Yleensä ne ovat sanaluokaltaan adjektiiveja (raidallinen, ongelmallinen, tavallinen). Virossa llinen-johtimen morfologinen vastine on -line, jolla kuitenkin on runsaasti paitsi adjektiivista myös substantiivista käyttöä: sillä voidaan johtaa muun muassa henkilöä, usein tekijää, tarkoittavia nimisanoja (esim. tööline 'työläinen', seeneline 'sienestäjä, pulmaline 'häävieras', kinoline 'elokuvissa kävijä’; ks. lähemmin Kasik 1998). 


\section{Erot kantasanan ja johdoksen suhteissa}

Suomen ja viron yhteisillä johdostyypeillä on toisinaan derivaatiosuhteissa kielten välisiä eroja. Esimerkiksi paikkaa osoittavat suomen $l A$-johdokset perustuvat aina nominikantaan: kana $>$ kanala, ruoka $>$ ruokala, sairas > sairaala. Silloinkin kun johdoksen taustalla on verbi, on ennen $l A$-johdinta verbikannan nominaalistava suffiksi, esimerkiksi myy/mä/lä, ui/ma/la, pes/u/la, parant/o/la. Sen sijaan virossa la-johdokset voivat olla sekä nomini- että suomesta poiketen myös verbikantaisia, kuten kana > kanala, söök > söökla, haige > haigla ja asu/da > asu/la 'taajama, yhdyskunta', maga/da > maga/la 'nukkumalähiö, uju/da > uju/la 'uimala'. Virossa ei kuitenkaan suomen tapaan muodosteta esimerkiksi nominikantaisia la-johdoksia sukulaisuutta osoittavista sanoista (vrt. sm. mummola, appela), mikä piirre liittyy 4. kohdan tapauksiin.

Suomen kielessä muodostetaan (i) $m O$-johdoksia toisin kuin $l A$ substantiiveja aina vain verbikannoista, ja johdostyyppi on varsin suosittu teko- ja olinpaikan nimityksissä, esimerkiksi katsomo, korjaamo, leipomo, matkustamo, ompelimo, äänittämö (Vesikansa 1978: 46-47; ISK 2004: 263). Virossa on vastaava $m u$-johdin tuotu kirjakieleen eteläviron murteista, ja sen käyttöön lienee jossain määrin vaikuttanut suomen (i)mO-suffiksi (Rätsep 2002: 307). Johdin ei ole virossa kovinkaan yleinen, ja paitsi vähälukuisia deverbaaleja, kuten elamu 'asuintalo, -rakennus' ja valamu 'pesuallas, lavuaari' (< valada 'kaataa'), sillä on muodostettu myös nominikantaisia johdoksia, esimerkiksi eramu 'omakotitalo', pühamu 'pyhäkkö' ja varamu kuv. 'varasto, aarreaitta. Tämän johdostyypin kohdalla, niin kuin usein muulloinkin suomen ja viron derivaatiojärjestelmien erikoispiirteitä tarkasteltaessa, tulee vastaan tietoisen kielenkehittelyn merkittävä osuus erojen syntyyn ja syvenemiseen, mistä muun muassa Päivi Rintala (1986: 44) on huomauttanut.

Verbiderivaation puolelta tarjoavat kielten eroja hyvin kuvastavan esimerkin ne-johdokset, jollaiset suomessa pohjautuvat aina nominikantaan: suuri > suurenee, kova > kovenee, paksu > paksunee. Sen sijaan virossa on nominikantaisten suureneda, kõveneda, pakseneda -tyyppisten 
teonsanojen ohella myös verbeistä muodostettuja johdoksia, esimerkiksi ava/da > ava/ne/da 'aueta, avautua', kogu/da > kogu/ne/da 'kokoontua', hävi/da > hävi/ne/da 'tuhoutua, hävitä vähitellen', sula/da > sula/ne/da 'sulautua', tüdi/da > tüdi/ne/da (sekä kantasanalla että johdoksella sama merkitys) 'kyllästyä. Tämä seikka lienee osaltaan vaikuttanut virossa potentiaalin väistymiseen (vrt. viron johdoksia suomen potentiaaleihin avannee, koonnee, hävinnee, sulanee; Remes 2009: 121-122).

\section{Erot johdostyyppien semanttisissa piirteissä}

Yhteisten johdostyyppien semanttisissa piirteissä on usein tärkeitä kielten välisiä eroja. Esimerkiksi johtimella sm. -(i)stA- / vir. -sta- voidaan kummassakin kielessä muodostaa nomineista muun muassa faktiivisia ja instruktiivisia verbejä: sm. ruskistaa, synkistää, maustaa, aseistaa vir. pruunistada, süngestada, maitsestada, relvastada. Suomessa sillä voidaan johtaa myös pyydystämistä tai keräämistä ilmaisevia eli kaptatiivisia verbejä, kuten sienestää, marjastaa ja rahastaa, mikä virossa ei ole mahdollista (poikkeus on kalastada, joka lienee suomalaislaina; Kasik 1992: 27). Siellä esimerkiksi verbi rahastada onkin instruktiivinen, merkitys 'rahoittaa', siis jokseenkin päinvastainen kuin suomessa, ja kaptatiivisuus on ilmaistava leksikaalisin keinoin: raha sisse kasseerida, maksu nõuda; samoin seenel käia 'sienestää ja marju korjata 'marjastaa'.

Verbiderivaatiossa suomella ja virolla on yhteinen johdin sm. -ttA- / vir. -ta-, jolla muodostettavien sanojen semanttinen kirjo on suuri, esimerkiksi sm. kasvattaa, jäähdyttää, muuttaa, pommittaa, koputtaa vir. kasvatada, jahutada, muuta, pommitada, koputada. Virosta puuttuu kuitenkin mahdollisuus johtaa sillä teettämistä ilmaisevia eli kuratiivisia verbejä, kuten suomessa luettaa, pesettää, kirjoituttaa (virossa ilmaistava leksikaalisin keinoin: lugema panna, lugeda lasta; pesta lasta; kirjutada lasta), sekä ns. tunnekausatiiveja, esimerkiksi suomen (minua) itkettää, naurattaa, suututtaa (vrt. vir. nutma panna/ajada; naerma ajada, naer tuleb peale; viha/pahameelt teha). 


\section{Johdostyyppien jakautuminen ja yhdistyminen}

Suomen kieli on viroa paremmin pitänyt vanhat johdostyypit toisistaan erillään. Jonkin verran tosin tavataan sellaistenkin analogista vuorovaikutusta, muun muassa ominaisuudennimien monikon siirtymisessä teonnimien paradigman mukaiseksi: rikkaus : rikkauden : rikkauksia (ei rikkausia; Hakulinen 1979: 145) kuten vastaus : vastauksen : vastauksia.

Virossa kielenmuutokset ovat toisinaan johtaneet johdostyyppien jakaantumiseen tai yhdistymiseen eli tilanteeseen, jossa yhtä suomen johdostyyppiä vastaa kaksi tai useampia tyyppejä ja kahta suomen johdostyyppiä vastaa vain yksi tyyppi. Esimerkiksi suomen deverbaalisten, taivutukseltaan yhdenmukaisten kaksitavuisten $e\left(<{ }^{*} e k\right)$-nominien murre, kaste, side, sade, kanne, kude virolaiset vastineet sijoittuvat, osin analogisen kehityksen vuoksi, neljään johdostyyppiin:
a) murre: murde: murret: murdeid 'murre'
kaste: 'kaste : kastet: 'kasteid
'kaste'
b) side : side : sidet : sidesid
'yhteys; viestitys'
c) sade : sademe : sadet : sademeid 'sade; sakka, saos' kanne: kandme: kannet: kandmeid 'kantoripa'
d) kude: koe: kude: kudesid 'kude; kudos'

Vain viron a-tyyppi vastaa suomen e-nominien taivutustyyppiä. Johdostyypin jakautumisen taustalla on virossa muun muassa käänteisen astevaihtelun mahdottomuus 1. kvantiteettiasteen sanoissa, mikä on johtanut paradigman astevaihteluttomuuteen tai joskus vaihtelusuunnan vaihtumiseen, sekä jälkitavuja kuluttanut äännekehitys. Seurauksena on ollut johdosten siirtyminen muihin johdostyyppeihin. (Remes 2009: 230-234; 2011: 176-179.)

Johdostyyppien yhdistymisestä tarjoavat hyvän esimerkin suomen (U)Us-johtimisten ominaisuudennimien, kuten rikkaus : rikkauden : rikkautta : rikkauksia, ja Us-johtimisten teonnimien, kuten vastaus : vastauksen : vastausta : vastauksia, virolaiset vastineet, jotka kuuluvat samaan tyyppiin: rikkus : rikkuse : rikkust ja vastus : vastuse : vastust. Virolaisille tuottaakin suomen johdostyyppien erottaminen vaikeuk- 
sia. Virossa tyyppien yhdistymiseen on päädytty osaltaan äänteellisesti samankaltaisten muotojen vuorovaikutuksen ja osaltaan analogisen äännevaihtelujen yksinkertaistumisen kautta (Remes 2009: 234-236). Suomessa ovat toisiinsa liittyneet vain johdostyyppien monikot, kun taas viron $u s$-nomineilla on juuri monikossa taivutuseroja, joihin ei kuitenkaan vaikuta johto-opillinen tausta vaan sanavartalon rakenne.

Ominaisuudennimi- ja teonnimijohdostyyppien yhdistyminen saattaa virossa joskus johtaa erikoiseen ja hämmentävään tilanteeseen, jossa kahdella homonyymisella johdoksella on vastakkainen merkitys. Esimerkiksi lekseemi pilvitus voi derivaatiotaustansa perusteella olla joko ominaisuudennimi merkityksessä 'pilvettömyys' tai teonnimi merkityksessä 'pilvisyys' (Vare 1981: 182):

$$
\begin{array}{ll}
\text { pilv }>\text { pilvitu 'pilvetön' } & >\text { pilvitus } \\
\text { pilv }>\text { pilvitada 'pilveillä } & >\text { pilvitus }(=\text { pilvisus }<\text { pilvine }<\text { pilv })
\end{array}
$$

\section{Johdostyyppi puuttuu toisesta kielestä}

Suomessa ja virossa on joukko kielikohtaisia, toisessa kielessä esiintymättömiä johdostyyppejä. Verbien osalta tosin Reet Kasik (1992: 25) toteaa, että "viron verbinjohdossa ei ole paljon sellaista, mikä suomen verbinjohdosta puuttuisi, mutta suomen verbinjohdossa on melko paljon sellaista, mitä viron derivaatiosysteemissä ei ole”. Virosta puuttuvat muun muassa $k s i$-johtimisten frekventatiivi- ja sensiiviverbiemme (lueksia, istuksia ja halveksia, kummeksia) vastinetyypit. Kielessä ei muutenkaan ole sensiiviverbejä, kuten ei myöskään kuratiivi- ja kaptatiivijohdoksia. $k s i$-johdosten mahdollisuus lienee osaltaan estynyt samanasuisen konditionaalisuffiksin takia (ks. Terho Itkonen 1983: 365-366). Virossa ei liioin tavata esimerkiksi $h k O$-johtimisia moderatiiviadjektiivejamme (huonohko, leveähkö) vastaavaa johdostyyppiä. Toisaalta muun muassa viron ryhmää ja paikkaa merkitseviltä mik-johdoksilta, kuten vestmik 'keskustelusanakirja' ja ristmik 'risteys', ja ldane-adjektiiveilta, kuten lüheldane 'lyhyehkö' ja vanaldane 'vanhahko', puuttuvat suomalaiset vastineet. 
Kielten kollektiivisten ja lokaalisten johdosten suhteita kuvastaa aikoinaan muuhun yhteyteen laatimani selvitys (Remes 2006: 235), josta ilmenee, että kielissä on vain viisi yhteistä johdostyyppiä, mutta neljätoista ainoastaan suomessa ja neljä virossa tavattavaa tyyppiä. Rajatapaus on virossa vain johtimena esiintyvä kond-aines, esimerkiksi lugejaskond 'lukijakunta', meeskond 'miehistö, joukkue', sugulaskond 'sukulaiset'. Sitä vastaa suomessa sana kunta, joka vanhastaan tavattiin ainoastaan yhdyssanojen jälkiosana: maakunta, kihlakunta, perhekunta, perikunta (Hakulinen 1948: 211). Isossa suomen kieliopissa (ISK 2004: 204, 552) huomautetaankin kunta-loppuisten yhdyssanojen kollektiivia ilmaisevasta merkityksestä. Varsinaisena johtimena kuntaa ei kuitenkaan voi pitää vokaalisointuun mukautumattomuuden ja nykyisen itsenäisen käytön vuoksi.

Johtimen puuttuminen toisesta kielestä voi olla luonteeltaan myös synkronista. Suomen supistumaverbijohdosten vastata : vastaan, hypätä : hyppään, luvata : lupaan, lisätä : lisään virolaisista vastineista puuttuu kielihistoriallisen kehityksen vuoksi johdin (Remes 2009: 242), ja diakronisesta taustasta kertoo vain taivutustyyppi (Kasik 1992: 29): vastata : vastan, hüpata : hüppan, tõmmata : tõmban 'vetää. Jos viron verbeissä on 1. kvantiteettiaste eli ensi tavu on aina lyhyt, ei paradigmatyypin vaihtumisen takia edes taivutus osoita taustaa, vaan verbit ovat mukautuneet johtamattomia perusverbejä sisältävään tyyppiin, esimerkiksi lubada : luban, lisada : lisan, kuten ei-supistumaverbit elada : elan, jagada : jagan. Kielihistoriallisestihan vanhat perusvartalot ovat usein olleet kaksitavuisia ja a-/ä-loppuisia (Erkki Itkonen 1961: 63, 67; Lehtinen 2007: 62). Siksi on tärkeä huomata, että kielenmuutosten vuoksi virossa vallitsee esimerkiksi sanojen luba ja lubada sekä lisa ja lisada välillä korrelaatio-, ei johtosuhde, kuten suomessa (vrt. lupa $>\operatorname{lupa/a/n}$ : luva/t/koon, lisä > lisä/ä/n : lisä/t/köön).

Suomen ja viron derivaatiosuhteiden kannalta ovat jossain määrin ongelmallisia sellaiset virossa verbeihin liittyvät tekoa ja teon tulosta merkitsevät lekseemit, joiden suomalaisina vastineina ovat kaksitavuiset $U$ - ja $O$-johtimiset substantiivit. Virossa äänteellisesti vastaava johdin - $u$ 
esiintyy nominatiivissa vain silloin, kun ensi tavu on lyhyt, kuten pesu, lugu, elu 'elämä, nägu 'kasvot' (vrt. sm. pesu, luku, elo, näkö). Muulloin nominatiivissa on loppuheiton aiheuttama johdinvokaalin kato, ja kielihistoriallinen johdostyyppi käy ilmi vasta taivutusmuodoista, esimerkiksi jooks : jooksu, käsk: käsu, kaev : kaevu, leid : leiu (vrt. sm. juokse- > juoksu, käske- > käsky, kaiva- > kaivo, löytä- > löytö). Virossa suhtautuminen jälkimmäisen ryhmän tapauksiin on ollut kahdenlaista. Tutkijoista muun muassa Silvi Vare (1981: 171; EKG I: 542-543) ei pidä tällaisten substantiivien $u$ :ta johtimena vaan vartalovokaalina, jolloin tietysti niiden ja vastaavien verbien suhde, kuten lekseemeissä jooks : jooksu ja joosta : jooksen, on kuvattava synkronisesti korrelaatiosuhteeksi eli toisin kuin suomessa, jossa johtosuhde on selkeä. Reet Kasik (1996: 94-95) puolestaan toteaa $u$-johdosten synkronisen analyysin ongelmallisuuden, mutta esittää johdosten joukossa myös loppuheittoiset jooks, käsk, leid -tyyppiset sanat. Mielestäni tällaista ratkaisua on hyödyllistä soveltaa ainakin silloin, kun kontrastiivisesta näkökulmasta, esimerkiksi kielenopetuksessa, käsitellään suomen $U$ - ja $O$-johdosten virolaisia vastineita (ks. myös Kasik 1989: 83).

\section{Lopuksi}

Suomen ja viron johtosuhteisiin kytkeytyvät olennaisesti taivutusmorfologiset erot, kuten osa edellä käsittelemistäni tapauksista osoittaa. Onkin tärkeä huomata, että suomalainen vironoppija ja virolainen suomenoppija eivät läheskään aina voi turvautua äidinkielen tukeen tutulta tuntuvien johdostyyppien taivutuksessa, mikä käytännössä merkitsee eroja johdinallomorfien suhteissa. Esimerkiksi suomen $t A r$-johdokset ovat kaksivartaloisia, vartalonvokaalina e: laulaja/tar : laulaja/ttare/n : laulaja/tar/ta. Virossa taas vastaava johdostyyppi on yksivartaloinen, vartalonvokaalina $i$ : laulja/tar : laulja/tari : laulja/tari (muoto laulja/tare on mon. partitiivi!). Virolainen johdin ei liioin ole astevaihtelullinen. Yksivartaloinen ja astevaihteluton on myös virolaisten kas-johdosten taivutus, ja johtimessa on $s$ vain nominatiivissa, esimerkiksi muna/kas : 
muna/ka : muna/ka/t 'mukulakivi', innu/kas : innu/ka : innu/ka/t, vrt. sm. muna/kas : muna/kkaa/n : muna/kas/ta, inno/kas : inno/kkaa/n : inno/kas/ta. Verbiderivaation puolella on merkittäviä eroja muun muassa suomen aina kaksivartaloisten $n e$ - ja itse-johdostyyppien virolaisten vastineiden taivutuksessa. Virossa on yleistynyt yksivartaloinen paradigma, ja johtimien asuina ovat aina -ne- ja -tse-: vir. suure/ne/da : suure/ne/b: suure/ne/gu, vali/tse/da : vali/tse/b : vali/se/gu 'hallita; vallita', vrt. sm. suureta : suure/ne/e : suure/t/koon, vallita : vall/itse/e : valli/t/koon.

Tarkastelemiini suomen ja viron johdostyyppien suhteiden erikoispiirteisiin on tärkeä kiinnittää huomiota lähisukuisen kielen sanaston opiskelussa ja käytössä. Yhtäläisyyksien ohella derivaatiojärjestelmistä löytyy myös runsaasti eroja, ja morfologian lohkoja verrattaessa voi todeta, että kielten välillä on erilaisuutta suhteellisesti enemmän johtoopissa kuin taivutuksessa ja nominien johtamisessa enemmän kuin verbiderivaatiossa.

\section{Lähteet}

EKG I = Erelt, Mati, Reet Kasik, Helle Metslang, Henno Rajandi, Kristiina Ross, Henn Saari, Kaja Tael, Silvi Vare 1995. Eesti keele grammatika I. Morfoloogia. Sõnamoodustus. Tallinn: Eesti TA KKI.

Hakulinen, Lauri 1948. Sanahistoriallista opetusainesta. - Virittäjä 52, 205-215.

Hakulinen, Lauri 1979. Suomen kielen rakenne ja kehitys. Neljäs, korjattu ja lisätty painos. Helsinki: Otava.

ISK 2004 = Hakulinen, Auli, Maria Vilkuna, Riitta Korhonen, Vesa Koivisto, Tarja Riitta Heinonen, Irja Alho. Iso suomen kielioppi. Suomalaisen Kirjallisuuden Seuran toimituksia 950. Helsinki: Suomalaisen Kirjallisuuden Seura.

Itkonen, Erkki 1961. Suomalais-ugrilaisen kielen- ja historiantutkimuksen alalta. Tietolipas 20. Helsinki: Suomalaisen Kirjallisuuden Seura.

Itkonen, Terho 1983. Välikatsaus suomen kielen juuriin. - Virittäjä 87, 349-383.

Kasik, Reet 1989. Eestin ja suomen verbinjohto. - Sananjalka 31, 81-91.

Kasik, Reet 1992. Viron ja suomen sananjohdon vertailua. - Helena Sulkala, Heli Laanekask (Toim.). Viron kielen päivä 6.5.1992. Oulun yliopiston suomen ja saamen kielen laitoksen tutkimusraportteja 35. Oulu: Oulun yliopisto, 25-33. 
Kasik, Reet 1996. Eesti keele sõnatuletus. Tartu Ülikooli Eesti keele õppetooli toimetised 3. Tartu: Tartu Ülikool.

Kasik, Reet 1998. Viron line-suffiksilliset tekijännimet. - Riho Grünthal, Johanna Laakso (Toim.). Oekeeta asijoo. Commentationes Fenno-Ugricae in honorem Seppo Suhonen sexagenarii 16.V.1998. Suomalais-Ugrilaisen Seuran toimituksia 228. Helsinki: Suomalais-Ugrilaisen Seura, 218-223.

Lehtinen, Tapani 2007. Kielen vuosituhannet. Suomen kielen kehitys kantauralista varhaissuomeen. Tietolipas 215. Helsinki: Suomalaisen Kirjallisuuden Seura.

Remes, Hannu 2006. Kollektiivisten ja paikkaa ilmaisevien johdostyyppien suhteista suomessa ja virossa. - Annekatrin Kaivapalu, Külvi Pruuli (Toim.). Lähivertailuja 17. Jyväskylä Studies in Humanities 53. Jyväskylä: University of Jyväskylä, 231-240.

Remes, Hannu 2009. Muodot kontrastissa. Suomen ja viron vertailevaa taivutusmorfologiaa. ActaUniversitas Ouluensis. B Humaniora 90. Oulu: Oulun yliopisto.

Remes, Hannu 2011. Käänteinen astevaihtelu ja paradigmojen restrukturoituminen - suomen ja viron taivutussuhteiden tarkastelua. - Mati Erelt (Toim.). Emakeele Seltsi aastaraamat 56. Tallinn: Teaduste Akadeemia Kirjastus, 172-185.

Rintala, Päivi 1986. Suomen ja viron johto-opillisten erojen syistä. - Päivi Rintala, Jüri Valge (Toim.). Lähivertailuja 2. Suomalais-virolainen virheanalyysiseminaari Turussa 10.-11.5.1986. Turun yliopiston suomalaisen ja yleisen kielitieteen laitoksen julkaisuja 31. Turku: Turun yliopisto, 44-68.

Rätsep, Huno 2002. Sõnaloo raamat. Tartu: Ilmamaa.

Simon, Valéria 2007. Johto-opin (sivu)rooli kielenopetuksessa. - Márta Csepregi, Virpi Masonen (Szerk.). Grammatíka és kontextus, új szempontok az uráli nyelvek kutatásában. Urálisztikai Tanulmányok 17. Budapest: ELTE Finnugor Tanszék, 295-301.

Vare, Silvi 1981. Nimisõnaliited tänapäeva eesti kirjakeeles. Eesti NSV TA KKI. Tallinn: Valgus.

Vesikansa, Jouko 1978. Johdokset. Nykysuomen oppaita 2. Helsinki: WSOY.

\section{Hannu Remes}

Linnanpolku 4

FI-87200 Kajaani

hannu.remes@uef.fi 


\title{
On the relationship between derivative types in Finnish and Estonian
}

\author{
HANNU REMES \\ University of Eastern Finland
}

Both in Finnish and in Estonian, the most frequent ways of word formation are compounding and derivation. The role which derivation can play in the acquisition of the lexicon of a sister language has not received very much attention in the research of language teaching and learning. Yet, for Finns and Estonians learning each other's language is facilitated by many shared derivative types; on the other hand, derivatives unknown to one's mother tongue may cause difficulties.

This article deals with the relationships between derivative types in Standard Finnish and Standard Estonian. Finns learning Estonian or vice versa must pay attention to several characteristics of noun and verb derivation. Even if words formed with the same derivational suffix appear in both languages, the meanings of the derivatives need not be similar. Or even if the derivational suffixes are cognate and their functions are similar, the bases of the derivatives may belong to different word classes. There may also be clear language-specific differences in the semantic characteristics of related derivative types: for instance, Estonian does not have curative (factitive) or captative verbs, although the cognates of Finnish curative and captative derivational suffixes do appear in Estonian. Furthermore, it is not unusual that a derivative type present in one of the sister languages is completely lacking in the other. Sometimes this is clearly due to language change, and the inflection may still reveal traces of an old derivative type.

The comparison between the morphological systems of Finnish and Estonian shows that there are more differences in derivation than in inflection, and more differences in noun than in verb derivation.

Keywords: contrastive linguistics; derivation; derivative types; derivational suffixes; Finnish; Estonian 